\title{
RELATIONSHIP BETWEEN ADOLESCENT DEPRESSION AND INSECURE ATTACHMENT: MEDIATING EFFECT OF PSYCHOLOGICAL CAPITAL
}

\author{
Yanmin Zhao ${ }^{1}, \mathrm{Li} \mathrm{Li}^{2}$ \& Xinyu Wang ${ }^{3}$ \\ ${ }^{1}$ Student Affairs Office, Wuhan University of Technology, Wuhan, China \\ ${ }^{2}$ College of Marxism, Huazhong Agricultural University, Wuhan, China \\ ${ }^{3}$ School of Law, Humanities and Sociology, Wuhan University of Technology, Wuhan, China \\ received: 7.8.2021; \\ revised: 11.10.2021; \\ accepted: 15.11 .2021
}

\section{SUMMARY}

Background: Depression is the primary factor influencing the mental health of adolescents. To explore the psychogenesis mechanism of adolescent depression, the relationships of adolescent depression with insecure attachment and psychological capital were discussed.

Subjects and methods: A total of 200 depression patients were selected as the research group through the simple sampling method from the adolescents accepting psychological counseling in Wuhan, China, from April to June 2020, and another 200 mentally healthy adolescents were taken as the control group. Positive Psycap Questionnaire (PPQ), Center Epidemiological Studies of Depression (CES-D) scale, and Experiences in Close Relationship (ECR) scale were distributed in the two groups to evaluate their psychological capital, depression, and insecure attachment.

Results: Compared with the control group, the avoidant attachment and anxious attachment scores are higher in the research group, but the score of each dimension of psychological capital and the total score is lower $(P<0.05)$. Avoidant attachment is positively correlated with both anxious attachment and depression and negatively correlated with psychological capital. Anxious attachment shows a positive correlation with depression and a negative correlation with psychological capital. A negative correlation is observed between psychological capital and depression $(P<0.05)$. Incomplete family, left-behind children, psychological capital, each dimension of psychological capital, avoidance attachment and anxious attachment are all independent influencing factors of adolescent depression, among which anxious attachment and avoidant attachment exert significant direct effects on adolescent depression, and psychological capital plays an incomplete mediating role in the relationships of anxious attachment and avoidant attachment with adolescent depression.

Conclusion: Psychological capital can relieve the depression degree, while insecure attachment has a positive predicting effect on adolescent depression, and psychological capital exerts an incomplete mediating effect on the relationship between insecure attachment and adolescent depression.

Key words: insecure attachment - depression - psychological capital - avoidant attachment - anxious attachment

$* * * * *$

\section{INTRODUCTION}

Depression refers to a restless and sad individual psychological state and a kind of negative emotional response expressed by individuals in face of internal or external stimuli (Harder et al. 2019). Adolescent stage is an important transitional stage from juveniles to adults and a key stage of physiological and psychological development. At the adolescent stage, the individual ego identity enjoys rapid development, with increasingly enhanced subjective initiative and everintensified pursuit and aspiration for freedom and independence (Young \& Mufson 2016). During this period, adolescents are susceptible to depression if perplexed by unhealthy emotions for a long time without good psychological quality (Bjezancevic et al. 2019). In recent years, the incidence of depression keeps rising among adolescents. A survey shows that the incidence of depressive symptoms exceeds $30 \%$ in adolescents (Suffoletto \& Aguilera 2016), and depression has become the main problem harming the mental health of adolescents. Understanding the occurrence mechanism and influencing factors of adolescent depression will be of great importance for positively and effectively preventing the occurrence of adolescent depression and promoting their mental health.

Attachment means an intense and persistent emotion generated by an individual to another specific person. According to the attachment theory, the attachment relationship of individuals with their caregivers in childhood will influence their future mental adaptation and interactions with others (Xu et al. 2017). In the latest studies, different attachment types have been interpreted from multiple levels. It is deemed that the attachment type will have a bearing on individual autobiographical memory processing mode, where secure attachment individuals can more easily extract their autobiographical memory, while insecure attachment individuals can hardly extract their early-stage memory or tend more to extract negative memory, and the extraction rate of negative memory is higher ( $\mathrm{Zhu}$ \& Zhu 2016). The partition criterion for secure 
attachment and insecure attachment depends on how the particles involved treat their own negative emotions. Secure attachment individuals believe their values and think that they can be liked by others and acquire help from others when encountering any difficulty, and insecure attachment individuals usually hold negative and suspicious attitudes towards their values (Ying et al. 2016). As indicated in a study (Jones et al. 2020), secure attachment people show relatively low avoidance index and anxiety index and higher mental health level with more positive cognition of themselves and others, while insecure attachment people usually can hardly establish emotional connections with others and can be perplexed by anxiety, depression and hostility, which will affect their mental health level. According to a literature report (You et al. 2020), insecure attachment is closely associated with the subthreshold depression of college students, and insecure adult attachment positively influences individual subthreshold depression level, in which self-esteem plays a mediating role. As a positive psychological resource, psychological capital is composed of four dimensions: self-efficacy, optimism, resilience and hope, with significant influences on adolescents' interpersonal relationships, schoolwork, happiness, mental health and sense of security. According to research findings (Mikulincer et al. 2003), selfefficacy can generate an effect on depression under the mediating effect of self-esteem. At present, the relationship between insecure attachment and individual depression and the role played by self-efficacy in this process have not been explored yet in China with adolescents as the research objects. Given this, two hypotheses were proposed in this study: Hypothesis 1, Insecure attachment can positively predict adolescent depression; Hypothesis 2, Self-efficacy plays a mediating role in the relationship between insecure attachment and adolescent depression.

By surveying the depression, psychological capital and insecure attachment status of adolescents, this study aims to test the mediating effect of self-efficacy based on the analysis of the correlations among psychological capital, insecure attachment and adolescent depression, to clarify the psychogenesis mechanism of adolescent depression and provide a reference for the prevention and treatment of adolescent depression.

\section{SUBJECTS AND METHODS}

\section{Study participants}

A total of 200 adolescent depression patients were selected as the research group through the simple sampling method in Wuhan, China, from April to June 2020, and another 200 mentally healthy adolescents accepting psychological counseling in the same period were selected as the control group. (1) Inclusion criteria: aging from 12 to 17 years old; normal communication and comprehension ability. The adolescents in the research group conformed to the diagnostic criteria for depression and were diagnosed with depressive symptoms. In the control group, the adolescents were diagnosed by psychologists without psychological problems like depression and anxiety, along with good mental health status. Informed consent was obtained from the adolescents who were willing to cooperate in the survey. (2) Exclusion criteria: depressive disorderinduced organic mental disorder; having the difficulty in understanding the questionnaires, thus failing to complete the questionnaires; those who were not willing to cooperate in the survey. The female adolescents accounted for a significantly higher proportion in the research group than that in the control group. The proportions of those with incomplete family and left-behind students were both higher than those in the control group $(P<0.05)$. The proportion of only children in the research group was approximate to that in the control group, and the difference was of no statistical significance $(P>0.05)$, as seen in Table 1 .

\section{Survey Method}

Questionnaire survey method was used. The research group members accepting uniform training acted as the investigators who explained the survey objectives, significance and questionnaire filling method using uniform instructions. The questionnaires were anonymously filled in strict accordance with the confidentiality principle. Besides, the questionnaires were distributed and collected on the field, a total of 714 questionnaires were distributed while 693 valid ones were recovered (200 ones in the control group and 493 ones in the research group), and the effective recovery rate was $97.06 \%$.

Table 1. Comparison of demographic characteristics between the two groups (n (\%))

\begin{tabular}{|c|c|c|c|c|c|c|c|c|}
\hline \multirow[t]{2}{*}{ Group } & \multicolumn{2}{|c|}{ Gender } & \multicolumn{2}{|c|}{$\begin{array}{l}\text { Whether being } \\
\text { an only child }\end{array}$} & \multicolumn{2}{|c|}{$\begin{array}{l}\text { Whether the family } \\
\text { is complete }\end{array}$} & \multicolumn{2}{|c|}{$\begin{array}{l}\text { Whether being } \\
\text { a left-behind student }\end{array}$} \\
\hline & Male & Female & Yes & No & Yes & No & Yes & No \\
\hline $\begin{array}{l}\text { Research group } \\
(n=200)\end{array}$ & $\begin{array}{c}80 \\
(40.00)\end{array}$ & $\begin{array}{c}120 \\
(60.00)\end{array}$ & $\begin{array}{c}104 \\
(52.00)\end{array}$ & $\begin{array}{c}96 \\
(48.00)\end{array}$ & $\begin{array}{c}41 \\
(20.50)\end{array}$ & $\begin{array}{c}159 \\
(79.50)\end{array}$ & $\begin{array}{c}140 \\
(70.00)\end{array}$ & $\begin{array}{c}60 \\
(30.00)\end{array}$ \\
\hline $\begin{array}{l}\text { Control group } \\
(n=200)\end{array}$ & $\begin{array}{c}101 \\
(50.50)\end{array}$ & $\begin{array}{c}99 \\
(49.50)\end{array}$ & $\begin{array}{c}116 \\
(58.00)\end{array}$ & $\begin{array}{c}84 \\
(42.00)\end{array}$ & $\begin{array}{c}162 \\
(81.00)\end{array}$ & $\begin{array}{c}38 \\
(19.00)\end{array}$ & $\begin{array}{c}70 \\
(35.00)\end{array}$ & $\begin{array}{c}130 \\
(65.00)\end{array}$ \\
\hline$\chi^{2}$ & \multicolumn{2}{|c|}{6.450} & \multicolumn{2}{|c|}{1.973} & \multicolumn{2}{|c|}{224.900} & \multicolumn{2}{|c|}{72.469} \\
\hline$P$ & \multicolumn{2}{|c|}{0.011} & \multicolumn{2}{|c|}{0.160} & \multicolumn{2}{|c|}{0.000} & \multicolumn{2}{|c|}{0.000} \\
\hline
\end{tabular}




\section{Positive Psycap Questionnaire (PPQ)}

This questionnaire was translated and revised by Wu et al. (2015) to evaluate the psychological capital level of respondents. The coefficient Cronbach $\alpha$ of subscale was $0.723-0.896$, and that of the total scale was 0.865 , indicating good reliability and validity. The questionnaire consisted of 20 items of four dimensions: selfefficacy, resilience, hope and optimism, and each item was scored using the Likert 6-level scoring method, ranging from 1 to 6 scores from "not met completely" to "fully met". The mean value of total scores of all items was namely the average total score of the questionnaire, and a higher score meant a higher psychological capital level.

\section{Center Epidemiological Studies of Depression (CES-D) scale}

This scale was translated and revised by $\mathrm{He}$ et al. (2013) for screening depression tendency. The Cronbach $\alpha$ coefficient of this scale was 0.877 , manifesting good reliability and validity. The scale included 20 items, and four-level scoring method was adopted, ranging from 0 to 3 scores from "almost no" to "nearly so all the time". The total scores of all items were added to acquire the total score of this scale, and a higher total score indicated the more serious depression, the total score $\leq 15$ was considered normal and $>15$ denoted the existence of depressive symptoms.

\section{Experiences in Close Relationship (ECR) scale}

The scale was the Chinese version of Experiences in Close Relationship (ECR) to evaluate the attachment tendency of respondents (Zhang et al. 2017). The Cronbach $\alpha$ coefficient of each dimension of this scale was 0.874 and 0.915 , respectively, indicating good reliability. The scale was composed of 36 items of two dimensions: avoidant attachment and anxious attachment. Single items were scored using the Likert 7-level scoring method (1-7 scores, from "disagree very much" to "agree very much"). A higher score meant a higher level of avoidant attachment/anxious attachment.

\section{Statistical Analysis}

The research data were processed via SPSS 20.0 software. The enumeration data were described by rate $(\%)$, and $\chi^{2}$ test was performed for data comparisons. The measurement data were expressed using mean \pm standard deviation $(\bar{x} \pm s)$, t-test or $\mathrm{F}$ test was carried out for data comparisons, and data relations were analyzed through Pearson correlation analysis and multiple stepwise regression analysis. As for the test of mediating effect, the maximum likelihood method was used to estimate the degree of fitting of models, and $P<0.05$ meant that the difference was statistically significant.

\section{RESULTS}

\section{Scoring of Attachment and Psychological Capital}

The scores of adolescent avoidant attachment and anxious attachment in the research group were significantly higher than those in the control group, and the score of each dimension (self-efficacy, resilience, hope and optimism) of psychological capital and total score were both markedly lower than those in the control group $(P<0.05)$, as seen in Table 2 .

\section{Correlation Analysis of Adolescent Attachment, Psychological Capital and Depression}

Adolescent avoidant attachment was positively correlated with both anxious attachment and depression and negatively correlated with psychological capital. Anxious attachment had a positive correlation with depression and a negative correlation with psychological capital. A negative correlation was observed between psychological capital and depression $(P<0.05)$, as seen in Table 3.

Table 2. Comparison of adolescent insecure attachment and psychological capital scores between the two groups $(\bar{x} \pm s$, scores $)$

\begin{tabular}{|c|c|c|c|c|c|c|c|}
\hline \multirow[b]{2}{*}{ Group } & \multicolumn{2}{|c|}{ Attachment } & \multicolumn{5}{|c|}{ Psychological capital } \\
\hline & $\begin{array}{c}\text { Avoidant } \\
\text { attachment }\end{array}$ & $\begin{array}{l}\text { Anxious } \\
\text { attachment }\end{array}$ & $\begin{array}{c}\text { Self- } \\
\text { efficacy }\end{array}$ & Resilience & Hope & Optimism & Total score \\
\hline $\begin{array}{l}\text { Research group } \\
(n=200)\end{array}$ & $\begin{array}{c}62.84 \\
\pm 12.39\end{array}$ & $\begin{array}{c}72.64 \\
\pm 17.21\end{array}$ & $\begin{array}{l}27.25 \\
\pm 2.25\end{array}$ & $\begin{array}{l}21.26 \\
\pm 2.16\end{array}$ & $\begin{array}{l}25.74 \\
\pm 3.24\end{array}$ & $\begin{array}{l}13.54 \\
\pm 2.21\end{array}$ & $\begin{array}{c}87.79 \\
\pm 12.85\end{array}$ \\
\hline $\begin{array}{l}\text { Control group } \\
(n=200)\end{array}$ & $\begin{array}{c}50.06 \\
\pm 14.08\end{array}$ & $\begin{array}{c}55.24 \\
\pm 15.72\end{array}$ & $\begin{array}{l}32.31 \\
\pm 1.78\end{array}$ & $\begin{array}{l}28.31 \\
\pm 3.25\end{array}$ & $\begin{array}{l}30.25 \\
\pm 2.64\end{array}$ & $\begin{array}{l}16.98 \\
\pm 3.24\end{array}$ & $\begin{array}{l}107.85 \\
\pm 14.05\end{array}$ \\
\hline $\mathrm{T}$ & 12.362 & 6.335 & 8.958 & 3.625 & 9.625 & 8.054 & 23.658 \\
\hline$P$ & 0.000 & 0.000 & 0.000 & 0.002 & 0.000 & 0.000 & 0.000 \\
\hline
\end{tabular}

Table 3. Correlation analysis of adolescent attachment, psychological capital and depression (r)

\begin{tabular}{lcccc}
\hline Variable & Avoidant attachment & Anxious attachment & Psychological capital & Depression \\
\hline Avoidant attachment & 1 & & & \\
Anxious attachment & 0.178 & 1 & & \\
Psychological capital & -0.246 & -0.318 & 1 & \\
Depression & 0.584 & 0.612 & -0.366 & 1 \\
\hline
\end{tabular}


Table 4. Multiple regression analysis results of influencing factors of adolescent depression

\begin{tabular}{lccccccc}
\hline Variable & $\mathrm{B}$ & S.E. & \multicolumn{1}{c}{$\beta$} & \multicolumn{1}{c}{$t$} & $P$ & OR & $95 \%$ CI \\
\hline Constant term & 4.965 & 8.269 & - & 10.765 & 0.000 & 0.958 & $0.745 \sim 3.001$ \\
Girl & 0.658 & 3.625 & 0.335 & 1.054 & 0.069 & 1.205 & $0.995 \sim 4.051$ \\
Incomplete family & 2.326 & 1.054 & 0.052 & 2.778 & 0.004 & 0.623 & $0.506 \sim 1.965$ \\
Left-behind children & 2.154 & 2.036 & 0.335 & 2.965 & 0.003 & 0.596 & $0.566 \sim 0.985$ \\
Psychological capital & & & & & & & \\
$\quad$ Self-efficacy & -1.254 & 1.658 & -0.064 & 3.878 & 0.000 & 0.966 & $0.874 \sim 4.051$ \\
$\quad$ Resilience & 4.965 & 8.269 & - & 10.765 & 0.000 & 0.958 & $0.745 \sim 3.001$ \\
$\quad$ Hope & 0.658 & 3.625 & 0.335 & 1.054 & 0.069 & 1.205 & $0.995 \sim 4.051$ \\
$\quad$ Optimism & 2.326 & 1.054 & 0.052 & 2.778 & 0.004 & 0.623 & $0.506 \sim 1.965$ \\
Attachment & & & & & & & \\
$\quad$ Avoidant attachment & 2.154 & 2.036 & 0.335 & 2.965 & 0.003 & 0.596 & $0.566 \sim 0.985$ \\
$\quad$ Anxious attachment & -1.254 & 1.658 & -0.064 & 3.878 & 0.000 & 0.966 & $0.874 \sim 4.051$ \\
\hline
\end{tabular}

Note: $\mathrm{R}^{2}=0.364 ; \quad \mathrm{F}=16.587 ; \quad P=0.000$

Table 5. Mediating effect analysis of psychological capital in the relationship between insecure attachment and adolescent depression

\begin{tabular}{|c|c|c|c|c|c|c|}
\hline \multirow{2}{*}{ Mediating variable } & \multirow{2}{*}{ Independent variable } & \multirow{2}{*}{$\begin{array}{l}\text { Mediating } \\
\text { effect value }\end{array}$} & \multirow{2}{*}{$\begin{array}{l}\text { Standard } \\
\text { error }\end{array}$} & \multirow{2}{*}{$P$} & \multicolumn{2}{|c|}{$95 \%$ confidence interval } \\
\hline & & & & & Lower limit & Upper limit \\
\hline \multirow{2}{*}{$\begin{array}{l}\text { Psychological } \\
\text { capital }\end{array}$} & Anxious attachment & -0.109 & 0.042 & 0.002 & -0.210 & -0.041 \\
\hline & Avoidant attachment & -0.089 & 0.039 & 0.003 & -0.203 & -0.029 \\
\hline
\end{tabular}

Table 6. Direct effect of insecure attachment on adolescent depression with mediating variable controlled

\begin{tabular}{lccccc}
\hline Independent variable & Direct effect value & Standard error & $P$ & \multicolumn{2}{c}{$95 \%$ confidence interval } \\
& & & & Lower limit & Upper limit \\
\hline Anxious attachment & -0.092 & 0.031 & 0.035 & -0.333 & 0.020 \\
Avoidant attachment & -0.074 & 0.022 & 0.012 & -0.378 & 0.035 \\
\hline
\end{tabular}

\section{Multiple Regression Analysis of Influencing Factors of Adolescent Depression}

Single-factor analysis showed that the scores of the items (girl, incomplete family and left-behind children) of statistical significance, each dimension of psychological capital and each dimension of attachment were taken as the independent variables and whether the adolescent was depressed as taken as the dependent variable to perform the multiple regression analysis. The results reflected that incomplete family, left-behind children, psychological capital, each dimension of psychological capital, avoidant attachment and anxious attachment were all the factors influencing adolescent depression. Each dimension of psychological capital exerted a negative predicting effect on depression, while incomplete family, left-behind children, avoidant attachment and anxious attachment generated a positive predicting effect on depression. The explanation rate of the above factors of the variation of adolescent depression was $36.4 \%$, as seen in Table 4 .

\section{Mediating Effect Test of Psychological Capital}

The mediating effect of psychological capital was tested through linear regression analysis. The results revealed that psychological capital exerted a significant mediating effect in the relationships of anxious attachment and avoidant attachment with adolescent depression $(P=0.002,0.003)$. After the mediating variable - psychological capital - was controlled, the direct effects of anxious attachment and avoidant attachment on adolescent depression were -0.092 and -0.074 , respectively $(P=0.031,0.022)$, indicating their significant influences on adolescent depression and reflecting that psychological capital played an incomplete mediating role in the relationships of anxious attachment and avoidant attachment with adolescent depression, as seen in Table 5 and Table 6.

\section{DISCUSSION}

The results in Table 1 showed that the girls accounted for a higher proportion in the research group than that in the control group, indicating that girls were more susceptible to depression than boys, which accorded with the conclusion in the literature report of Hua et al. (2018). This might be because girls were more scrupulous and sensitive and their emotions were more easily affected by external factors. It could also be seen from Table 1 that in comparison with the mentally healthy adolescents, the depressed adolescents with incomplete family and left-behind students both accounted for higher proportions, hinting that family relation might influence the mental health of adolescents, and it was especially closely related to adolescent depression. The possible reason was that growing incomplete family 
and accompanied by both parents, the individuals could perceive the love from their parents, thus contributing to the sense of security. While completing the individualized differentiation to form ego identity, such individuals could keep connections with their families, positively contact others, continuously accumulate new experiences, explore the external world and generate a high-level self-identity, so they were rarely depressed.

As seen in Table 2, the adolescent avoidant attachment and anxious attachment scores in both groups were at medium and high levels, which were in line with the conclusion in a related literature report in China (Lin et al. 2018). Avoidant attachment and anxious attachment are the two main manifestation forms of insecure attachment, where avoidant attachment people deny their attachment demand, avoid contact with others and even keep away from others, and will not seek help from others when encountering a problem (Lin et al. 2017). Anxious attachment individuals usually show higher attachment demands and extremely strong desire to monopolize, with excessive negative emotions to attract attention and seek help from others. This reflects that insecure attachment has a high incidence rate among Chinese adolescents, which may be ascribed to the traditional educational pattern in China. Chinese people restrain themselves in the emotional expression, the parent-child relationship is relatively alienated in the family education, and so adolescent attachment is mainly manifested in the form of avoidant attachment or anxious attachment (Bakker et al. 2017). According to the attachment scores of the two groups as seen in Table 2, both the anxious attachment and avoidant attachment scores in the research group were significantly higher than those in the control group. It appeared that the attachment type was correlated with depressive emotion. Compared with secure attachment, insecure attachment individuals could more easily generate depressive emotions.

As seen in Table 3, adolescent attachment, psychological capital and depression were closely related. Each dimension (self-efficacy, optimism, resilience and hope) of psychological capital showed a negative predicting effect on depression, namely, the adolescents with high psychological capital levels were less probable to feel the depressive symptoms. Psychological capital is a positive mental state gradually formed in the individual growth process. According to a study (Bodden et al. 2018), psychological capital has close correlations with negative emotions like depression and anxiety, and individuals with higher psychological capital levels are less probable to have negative emotions. As pointed out in the report (Carly \& Rapee 2018), psychological capital has a significant predicting effect on individual sense of security, along with an obvious relieving effect on depression, which accords with the results in this paper. To figure out why, those with high psychological capital level believe their ability to solve problems and are more inclined to adopt positive and effective coping strategies so that the problems can be effectively solved which can mitigate the mental pressure brought by various difficulties and setbacks and further restrain negative emotions like depression and anxiety (Jones et al. 2017). On the other hand, those with high psychological capital levels can conduct active attribution to realize the goals, hold optimistic expectations for the development of events and are confident in undertaking very challenging jobs. Moreover, they will spare no efforts to overcome difficulties and achieve their goals, but will never back down. People of this personality trait can learn and live more efficiently and hold optimistic attitudes towards problems, and besides, they are free from sense of frustration, not to mention negative emotions like anxiety and depression (Liese et al. 2020).

It could be seen from Table 4 that depression could be positively predicted by avoidant attachment and anxious attachment. As stated in a study (Colburn et al. 2020), the character type prone to depression is consistent with the attachment types like anxiety and avoidance. Insecure attachment individuals are more susceptible to depressive symptoms, while secure attachment ones are less probable to experience depressive symptoms, possibly because avoidant and anxious attachment individuals could hardly realize selfaffirmation or find and affirm their own merits, lacking clear self-concepts. Moreover, they will choose to avoid setbacks and difficulties and think that they are not able to solve problems, so they can be easily stuck in negative emotions, and their psychology and emotions can be easily immersed in the negative event and fail to be divorced from it, thus further aggravating their negative emotions. In comparison with secure attachment people, insecure attachment people can acquire less social support when encountering a traumatic event and can hardly be recovered from such an event (Stafford et al. 2020, Melnyk et al. 2019, Antičević et al. 2019). On the other hand, insecure attachment individuals are usually of low empathy with higher rumination levels, which will also indirectly influence their social support and increase the risk of depression. In addition, the internal mode of thinking of insecure attachment individuals is more inclined to negative ego, e.g., being certain to be refused and not worthy of love, thus generating hopeless feelings and increasing depressive symptoms. It could also be seen from Table 4 that incomplete family and left-behind children exerted positive predicting effects on adolescent depression. Compared with complete family and non-left-behind adolescents, the adolescents with incomplete family and left-behind experience were more liable to depression. This was possible because the adolescents from single-parent families and those left behind could perceive the missing of parents' care, which generated negative impacts on their mental growth and formation of their personality, so such adolescents were more susceptible to depressive symptoms, or relatively speaking, their depressive symptoms were relatively more serious (Sheinbaum et al. 2015). 
Through the mediating effect test results in Table 5 and Table 6, psychological capital played a significant partial mediating role in the relationships of anxious attachment and avoidant attachment with adolescent depression, which accorded with the conclusion of a similar literature report (Yan 2020) and verified the mediating effect of psychological capital, a positive psychological factor, on adolescent insecure attachment and depression. Moreover, this reflected that insecure attachment could not only directly influence adolescent depression but also indirectly affect it via psychological capital. From the theoretical framework of psychological capital, it could be obtained that insecure attachment could increase the risk of adolescent depression, but psychological capital, which was a positive psychological factor, facilitated individuals to actively seek positive psychological resources, improve their self-efficacy, be full of hope, acquire positive mental state and further relieve the negative impacts caused by insecure attachment to adolescents and reduce the incidence of depression.

\section{CONCLUSION}

Adolescent depression is closely related to psychological capital and insecure attachment, among which psychological capital can relieve the depression degree, insecure attachment exerts a positive predicting effect on adolescent depression, and psychological capital plays an incomplete mediating role in the relationship between insecure attachment and adolescent depression. Meanwhile, adolescent depression can also be positively predicted by incomplete family and left-behind children. In complete family relationships, if parents can accompany their children more, this can help to alleviate adolescent insecure attachment and change the attachment mode, and an effective path to the prevention and treatment of adolescent depression lies in increasing the psychological capital.

\section{Acknowledgements: None.}

\section{Conflict of interest: None to declare.}

\section{Contribution of individual authors:}

Yanmin Zhao: Conception and design, analysis.

Li Li: Planning and designing data collection, statistical analysis, draft preparation.

Xinyu Wang: Material preparation, data collection, approval of the final version.

All authors have read and agreed to the published version of the manuscript.

\section{References}

1. Antičević $V$, Šošić S, Britvić D: Emotional competence and coping mechanisms in Croatian women with Borderline personality disorder: the role of attachment. Psychiatr Danub 2019; 31(1):88-94
2. Bakker DJ, Lyons ST, Conlon PD: An exploration of the relationship between psychological capital and depression among first-year doctor of veterinary medicine students. Journal of Veterinary Medical Education 2017; 44:50-62

3. Bježančević M, Groznica Hržić I, Dodig-Ćurković K: SelfInjury in Adolescents: A Five-Year Study of Characteristics and Trends. Psychiatr Danub 2019; 31:413-420

4. Bodden DHM, Stikkelbroek Y, Dirksen CD: Societal burden of adolescent depression, an overview and costof-illness study. Journal of Affective Disorders 2018; 241:256-262

5. Carly J. Rapee RM: Depression literacy and stigma influence how parents perceive and respond to adolescent depressive symptoms. Journal of Affective Disorders 2018; 241:599-607

6. Colburn MD, Harris E, Lehmann C, Widdice LE, Klein MD: Adolescent depression curriculum impact on pediatric residents' knowledge and confidence to diagnose and manage depression. Journal of Adolescent Health 2020; 66(2):240-246

7. Fallucco EM, James L, Smotherman C, Greco P: Impact of experiential training with standardized patients on screening and diagnosis of adolescent depression in primary care. Journal of Adolescent Health Official Publication of the Society for Adolescent Medicine 2019; 65(1):57-62

8. Harder VS, Barry SE, French S, Consigli AB, Frankowski $B L$ : Improving adolescent depression screening in pediatric primary care. Academic Pediatrics 2019; 19(8):925-933

9. He J, Chen ZY, Guo F, Zhang J, Yang YP, Wang $Q: A$ short Chinese version of center for epidemiologic studies depression scale. Chinese Journal of Behavioral Medicine and Brain Science 2013; 22(12):1133-1136

10. Hua X, Li WW, Zhang Y, Wang Y: Relationship of belief in a just world with depression and anxiety in migrant children and left-behind children. Chinese Mental Health Journal 2018; 32(2):142-147

11. Jones RB, Thapar A, Stone Z, Thapar A, Jones I, Smith D: Psychoeducational interventions in adolescent depression: a systematic review. Patient Education \& Counseling 2017; 101(5):804-816

12. Jones L, Staples J, Salgado E, Garabrant J, Salyers M: Mind-body skills groups: a possible approach for addressing adolescent depression in primary care. Journal of Adolescent Health 2020; 66(2):S5-S6

13. Liese BS, Kim HS, Hodgins DC: Insecure attachment and addiction: testing the mediating role of emotion dysregulation in four potentially addictive behaviors. Addictive behaviors 2020; 107:106432

14. Lin JP, Chen LD, Liu SQ: Relationship of interpersonal stress and depression, self-identity and subjective wellbeing among college students: the moderating role of psychological capital. Modern Preventive Medicine 2018; 45(11):99-102

15. Lin G, Qiu W, Wei L, Yang BL: The influence of college students' psychological capital on depression and anxiety. Journal of Jinzhou Medical University (Social Science Edition) 2017; 15(3):61-64

16. Melnyk BM: Reducing healthcare costs for mental health hospitalizations with the evidence-based cope program for child and adolescent depression and anxiety: a cost analysis. Journal of Pediatric Health Care 2019; 34(2):117-121 
17. Mikulincer M, Shaver PR, Pereg D: Attachment theory and affect regulation: the dynamics, development, and cognitive consequences of attachment-related strategies. Motivation and Emotion 2003; 27(2):77-102

18. Stafford AM, Garbuz T, Etter DJ, Adams ZW, Hulvershorn LA, Downs SM, Aalsma MC: The natural course of adolescent depression treatment in the primary care setting. Journal of Pediatric Health Care 2020; 34:38-46

19. Suffoletto B, Aguilera A: Expanding adolescent depression prevention through simple communication technologies. Journal of Adolescent Health 2016; 59(4):373-374

20. Xu MF, Hou ZJ, Li X, Wang DN, Qian J: A review of attachment relationship in psychotherapy. Chinese Journal of Clinical Psychology 2017; 25(2):319-325

21. Yan $W$ : The effects of college students' parental and peer attachment on depression: the mediating role of social support and self-efficacy. Advances in Psychology 2020; 10(3):269-275
22. Ying L, Jing Z, Xu C: Cognitive neural characteristics of the emotion regulation strategies in different attachment styles. Journal of Psychological Science 2016; 39:109-115

23. You MY, Song XH, Tan X, Du J, Kong JH: Attachment and subthreshold depression in medical college students: Mediating effect of self-esteem. China Journal of Health Psychology 2020; 28(8):1211-1215

24. Young J, Mufson L: 25.2 interpersonal psychotherapy: adolescent skills training for the prevention of adolescent depression. Journal of the American Academy of Child \& Adolescent Psychiatry 2016; 55(10):S38-S39

25. Zhang $P$, Zhang YB, Han RX, Liu XP: Reliability and validity test of Chinese version of the experience of close relationship in adolescents. Chinese Journal of Clinical Psychology 2017; 25(5):873-876

26. Zhu LS, Zhu ZH: Relation of attachment type to cooperation in college students. Chinese Mental Health Journal 2016; 30(2):148-151

\section{Correspondence:}

Xinyu Wang, Postgraduate

School of Law, Humanities and Sociology, Wuhan University of Technology

\#205 Luoshi Road, Hongshan District, 430070 Wuhan, China

E-mail: sylvieseveride@163.com 